\title{
Resultados Iniciais do Transplante de Células de Medula Óssea para o Miocárdio de Pacientes com Insuficiência Cardíaca de Etiologia Chagásica
}

\author{
Early Results of Bone Marrow Cell Transplantation to the Myocardium of Patients with \\ Heart Failure due to Chagas Disease
}

Fábio Vilas-Boas', Gilson S. Feitosa1', Milena B.P. Soares², Augusto Mota¹, Joel Alves Pinho-Filho', Augusto José Gonçalves Almeida1, Marcus Vinicius Andrade1, Heitor G. Carvalho1,

Adriano Dourado-Oliveira1', Ricardo Ribeiro-dos-Santos²

Hospital Santa Izabel', Centro de Pesquisas Gonçalo Moniz - Fundação Oswaldo Cruz² - Salvador, BA

\section{Objetivo}

Avaliar efeitos precoces do transplante de células de medula óssea para o miocárdio de pacientes com insuficiência cardíaca (IC) de etiologia chagásica.

\section{Métodos}

A amostra consistiu de 28 pacientes, idade média 52,2 $\pm 9,9$ anos, 24 masculinos, 25 em classe NYHA III e 3 em NYHA IV, apesar de tratamento otimizado. 0 procedimento consistiu na aspiração de $50 \mathrm{ml}$ de medula óssea, separação da fração mononuclear e injeção intracoronariana. Foram avaliados os efeitos sobre a fração de ejeção ventricular esquerda (FEVE), distância no teste de 6 minutos, qualidade de vida, classe NYHA, efeitos arritmogênicos e bioquímicos.

\section{Resultados}

Não houve complicações relacionadas diretamente ao procedimento. A fração de ejeção ventricular esquerda em repouso antes do transplante era $20,1 \pm 6,8 \%$ e,

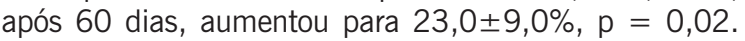
Houve melhora da classe NYHA $(3,1 \pm 0,3$ para $1,8 \pm 0,5$; $p<0.0001)$; qualidade de vida $(50,9 \pm 11,7$ para $21,8 \pm 13,4 ; p<0.0001$ ); distância caminhada (355 \pm 136 $\mathrm{m}$ para $443 \pm 110 \mathrm{~m} ; \mathrm{p}=0,003)$. O número de extrassístoles ventriculares em $24 \mathrm{~h}$ apresentou tendência à elevação (5.322 \pm 4.977 para 7.441 $\pm 7.955 ; p=0,062)$, porém sem incremento dos episódios de taquicardia ventricular (61 \pm 127 para $54 \pm 127 ; p=0,27$ ).

\section{Conclusão}

Nossos dados demonstram que a injeção intracoronariana de células mononucleares da medula óssea é exeqüível e sugere ser potencialmente segura e eficaz em pacientes com IC de etiologia chagásica.

\section{Palavras-chave}

Células-tronco, insuficiência cardíaca, doença de Chagas, terapia celular, miocardiopatia dilatada.

\section{ОвJeCtIVE}

To evaluate early effects of bone marrow cell transplantation to the myocardium of patients with heart failure (CHF) due to Chagas disease.

\section{Methods}

We studied 28 patients (mean age $52.2 \pm 9.9$ ), of whom 24 were male. Despite optimized treatment, 25 patients were in NYHA class III and three patients, in NYHA class IV. The procedure consisted of aspiration of $50 \mathrm{~mL}$ of bone marrow, separation of the mononuclear fraction, and intracoronary injection. Effects on left ventricle ejection fraction (LVEF), distance walked in the six-minute walking test, quality-of-life, NYHA class, arrhythmogenic and biochemical parameters, were all evaluated.

\section{RESULTS}

There were no complications directly related to the procedure. Baseline left ventricular ejection fraction was $20.1 \pm 6.8 \%$, and 60 days after transplantation it increased to $23.0 \pm 9.0 \%, p=0.02$. Significant improvements were observed in the NYHA class (3.1 $1 \pm$ 0.3 to $1.8 \pm 0.5 ; p<0.0001$ ); quality-of-life (50.9 \pm 11.7 to $21.8 \pm 13.4 ; p<0.0001)$; and distance walked in six minutes $(355 \pm 136 \mathrm{~m}$ to $443 \pm 110$ $m ; p=0,003)$. The number of ventricular premature beats in 24 hours tended to increase (5,322 \pm 4,977 to 7,441 $\pm 7,955 ; p=0,062$ ), but without increase in ventricular tachycardia episodes $(61 \pm 127$ to $54 \pm$ 127; $p=0.27$ ).

\section{Conclusion}

Our data demonstrate for the first time that intracoronary injection of bone marrow mononuclear cells is feasible and suggest that it may be potentially safe and effective in patients with CHF due to Chagas disease.

\section{KEY WORDS}

Stem cell, heart failure, Chagas disease, cell therapy, dilated cardiomyopathy.

Correspondência: Fábio Vilas-Boas - Praça Almeida Couto, 500, Nazaré - 40050-410, Salvador - BA 
A capacidade das células-tronco de medula óssea de se diferenciarem em cardiomiócitos tem sido demonstrada principalmente em modelos experimentais de infarto do miocárdio ${ }^{1-3}$. Embora algum grau de controvérsia exista quanto à plasticidade dessas células, tais observações levaram investigadores a examinarem, em humanos, o papel dessas células no tratamento do infarto do miocárdio e da insuficiência cardíaca (IC) de etiologia isquêmica, com resultados iniciais promissores ${ }^{4-6}$.

No Brasil, a doença de Chagas é um dos principais contribuintes do quadro nosológico da insuficiência cardíaca. Estimativas sorológicas mostram que, no Brasil, oito a nove milhões de pessoas são infectadas pelo Trypanosoma cruzi e que 30 a $40 \%$ delas podem ter algum grau de comprometimento cardíaco ${ }^{7}$. Os pacientes portadores de insuficiência cardíaca devida à cardiopatia chagásica crônica evoluem com grave disfunção sistólica devida à miocardite crônica e conseqüente fibrose ${ }^{8}$.

Os mecanismos etiopatogênicos e fisiopatológicos que promovem a doença de Chagas tornam a terapia com células-tronco atraente. A presença de miocardite persistente e a demonstração da produção aumentada de citocinas pelo miocárdio de pacientes com IC de etiologia chagásica sugerem a existência de um ambiente atrativo para o "homing" e para a fixação das célulastronco ${ }^{9}$. Portanto, ao contrário do tratamento de outras cardiopatias onde pouca inflamação é encontrada, na cardiopatia chagásica pode-se supor que células-tronco circulantes migrem para o miocárdio, recrutadas pelos sinais inflamatórios difundidos por todo o órgão.

Estudos sobre o uso de células-tronco de medula óssea no tratamento da cardiomiopatia chagásica crônica experimental demonstraram que camundongos chagásicos crônicos apresentaram uma significativa diminuição da inflamação e regressão da fibrose após dois meses de tratamento com células de medula óssea adultas, em comparação com animais controle ${ }^{10}$.

0 relato do primeiro caso de transplante de célulastronco de medula óssea para o miocárdio de paciente com insuficiência cardíaca de etiologia chagásica foi feito por nosso grupo e revelou melhora da função ventricular, qualidade de vida e capacidade funcional ${ }^{11}$.

O objetivo do presente estudo é avaliar a exeqüibilidade e segurança do transplante autólogo de células mononucleares da medula óssea em pacientes portadores de insuficiência cardíaca de etiologia chagásica, bem como identificar evidências iniciais de eficácia do procedimento.

\section{MÉtodos}

Foi delineado um ensaio clínico de fase 1, aberto, não-controlado, de casos selecionados de IC crônica de etiologia chagásica, realizado em centro único, no Hospital Santa Izabel da Santa Casa de Misericórdia da Bahia, no Brasil.
Foram incluídos, consecutivamente, pacientes com IC crônica, de etiologia chagásica, com fração de ejeção de ventrículo esquerdo (VE) menor que $40 \%$ ao ecocardiograma, de ambos os sexos, idades entre 20 e 70 anos e em classes funcionais III e IV (NYHA), em uso de terapia crônica otimizada para ICC (digoxina, diuréticos, inibidores da enzima conversora de angiotensina, com ou sem betabloqueador ou antagonistas dos receptores de angiotensina II), e que se mantivessem estáveis nessa condição no mês que antecedeu ao experimento.

Foram excluídos pacientes com presença de outras afecções patológicas sistêmicas associadas; tais como infecções ou neoplasias; doenças auto-imunes; doenças neurodegenerativas; insuficiência cardíaca aguda ou descompensada agudamente; doenças hematológicas prévias; coagulopatias; insuficiência hepática; insuficiência renal moderada (creatinina acima de $2 \mathrm{mg} / \mathrm{dl}$ ); história prévia de doença pulmonar obstrutiva crônica; implante de marca-passo ressincronizador interventricular há menos de 90 dias; mulheres com potencial de engravidar e pacientes com doença arterial coronariana detectada previamente ou após realização de coronariografia.

0 presente protocolo foi aprovado pela Comissão Nacional de Ética em Pesquisa (Registro CONEP n 4108; Processo $\left.n^{\circ} 25000.054219 / 2002 / 20\right)$. Os pacientes foram detalhadamente informados sobre todos os procedimentos de investigação e, após leitura completa e aceitação por escrito do termo de consentimento livre e esclarecido, foram incluídos no estudo.

Todos os pacientes foram submetidos à avaliação clínica inicial, com registro basal de dados clínicos e das seguintes variáveis: a) Classe funcional (NYHA), b) Escore de qualidade de vida do "Minnesota Living With Heart Failure Questionnaire"; c) Avaliação hematológica e bioquímica; d) Eletrocardiograma de 12 derivações; e) Ecocardiograma transtorácico; f) Ventriculografia radioisotópica; g) Teste de caminhada de 6 minutos; h) Holter 24h. Após o procedimento os pacientes eram encaminhados para a Unidade de Terapia Intensiva, onde permaneciam monitorizados por, pelo menos 24h. Não havendo intercorrências, eram transferidos para a enfermaria, onde permaneciam até completar o mínimo de 05 dias de acompanhamento hospitalar. Toda a avaliação clínica, laboratorial e por exames complementares foi repetida após 30 e 60 dias.

Para avaliar a ocorrência de possível dano miocárdico pela injeção de células de medula óssea no coração, foram realizados, seriadamente (a cada $6 \mathrm{~h}$ durante as primeiras 24h), dosagens de marcadores de necrose miocárdica (CK-MB e troponina I), assim como eletrocardiogramas. Para investigar o potencial desencadeamento de arritmias cardíacas como complicação da injeção de células, os pacientes foram submetidos a avaliações com eletrocardiografia ambulatorial (sistema Holter) 24h antes do procedimento e periodicamente desde então (após 24 h, 30 d e 60 d). 
Transplante de células-tronco - Na manhã do procedimento os pacientes eram encaminhados ao centro de hemodinâmica, em jejum. De cada paciente eram aspirados $50 \mathrm{ml}$ de conteúdo da medula óssea através de cinco punções da crista ilíaca posterior direita e cinco da crista ilíaca posterior esquerda, cada uma com retirada de cinco $\mathrm{ml}$, sob anestesia local com lidocaína $2 \%$ e sedação venosa com midazolan. 0 aspirado de medula era submetido a processo de filtragem de resíduos de gordura e fragmentos ósseos (filtro de aço inoxidável, Universidade de Washington), seguido de centrifugação por gradiente de Ficoll Hystopaque (Amersham Pharmacia, produto licenciado para uso humano). A fração de células mononucleares isolada era então diluída em solução salina estéril e centrifugada novamente. Uma amostra era submetida à contagem e ao teste de viabilidade celular. Ao término do processo, a amostra era diluída em $20 \mathrm{ml}$ de salina. Imediatamente antes da injeção intracoronária, os pacientes eram submetidos a cateterismo cardíaco esquerdo por punção femoral, seguido de coronariografia. Havendo evidências de doença coronariana hemodinamicamente significativa (estenoses $\geq 50 \%$ ) o paciente era excluído do estudo. A solução contendo as células era injetada lentamente, durante 10 minutos, no sistema coronariano direito e esquerdo. Dez $\mathrm{ml}$ da solução eram injetados na artéria coronária descendente anterior, $5 \mathrm{ml}$ na artéria coronária direita e $5 \mathrm{ml}$ na artéria circunflexa esquerda.

Após 25 dias do procedimento, os pacientes recebiam injeções diárias por via SC durante cinco dias de G-CSF humano (Granulokine ${ }^{\circledR}$ ) na dose de $5 \mathrm{mcg} / \mathrm{kg} / \mathrm{dia}$ para induzir a mobilização de células-tronco da medula óssea para o sangue periférico, com o objetivo de promover reforço de oferta de células-tronco para o reparo das lesões. Em estudos realizados utilizando um modelo experimental de miocardite chagásica, a combinação da terapia celular com o tratamento com G-CSF causou uma redução significativamente maior do número de células inflamatórias do que somente a terapia celular (dados não publicados).

0 teste de caminhada de 6 minutos foi realizado conforme protocolo utilizado por Bitner e cols. no estudo SOLVD ${ }^{12}$. Após 15 minutos de descanso, um novo teste era realizado e a média das distâncias caminhadas nos dois testes era empregada como resultado. Para a avaliação da qualidade de vida, foi utilizado o questionário da Universidade de Minnesota "Living with Heart Failure Questionnaire"13, validado em nosso país por Carrara e cols $^{14}$. As avaliações ecocardiográficas foram realizadas pelo mesmo observador, que não tinha acesso aos exames anteriores, em equipamento da marca Hewllet Packard, modelo Sonos 5500 (Seattle, WA, EUA), sendo utilizado o método de Simpson modificado, para obtenção da fração de ejeção do ventrículo esquerdo ${ }^{15,16}$. As gravações do Holter foram feitas em equipamento digital da marca Dynamis modelo 3000 ECO e analisadas em equipamento Burdick, com software AltairPC Holter System.
Análise estatística - A análise estatística foi realizada, utilizando-se o programa SPSS (Statistical Package for Social Sciences) for Windows versão 9.0. As variáveis contínuas foram expressas em médias \pm desvios-padrão. Para testar a normalidade da distribuição das variáveis, foi aplicado o teste de Kolmogorov-Smirnov. Como as variáveis apresentavam distribuição não normal, foram utilizados testes não-paramétricos. Todas as comparações foram bicaudais. Foram considerados estatisticamente significantes os valores de $p<0,05$.

Fontes de financiamento do estudo - Esse estudo contou com o financiamento das seguintes instituições: Fundação de Amparo à Pesquisa do Estado da Bahia (FAPESB); Financiadora de Estudos e Projetos do CNPq (FINEP) e Instituto do Milênio de Bioengenharia Tecidual. Os autores declaram não ter nenhum tipo de conflito de interesses.

\section{Resultados}

Foram selecionados 30 pacientes, sendo dois excluídos após a coleta de medula óssea: um paciente por doença coronariana após cateterismo e outro paciente por problemas técnicos com o equipamento. As principais características dos 28 pacientes estudados se encontram descritas na tabela 1 . A análise do perfil clínico revela uma população com avançado estágio da doença e vários marcadores de gravidade. Todos os pacientes estavam extremamente limitados, em classes funcionais III e IV, apesar de tratamento clínico otimizado com múltiplos

\section{Tabela 1 - Características Clínicas e Laboratoriais dos Pacientes Estudados}

\begin{tabular}{lc} 
& $(\mathrm{n}=28)$ \\
\hline Idade (anos) & $52,2 \pm 9,9$ \\
Sexo masculino (n) & 24 \\
CF (NYHA) n & \\
$\quad$ III & 25 \\
$\quad$ IV & 4 \\
TC 6 min (m) & $355 \pm 136$ \\
Fração de ejeção de VE (\%) & $20,1 \pm 6,8$ \\
DDFVE (mm) & $72,6 \pm 8,9$ \\
EQV & $50,9 \pm 11,7$ \\
Sódio sérico (meq/l) & $131 \pm 7,6$ \\
Uréia sérica (mg/dl) & $69 \pm 36,8$ \\
Creatinina & $1,4 \pm 0,4$ \\
Digoxina (\%) & 95 \\
Furosemida (\%) & 85 \\
Hidroclorotiazida (\%) & 35 \\
IECA ou BRA (\%) & 85 \\
Betabloqueadores (\%) & 55
\end{tabular}

$n=$ número de pacientes; $C F=$ classe funcional (NYHA); EQV = escore de qualidade de vida de Minnesota; TC $6 \mathrm{~min}=$ teste de caminhada de seis minutos em corredor; DDFVE = diâmetro diastólico final do ventrículo esquerdo; IECA = inibidor da enzima conversora de angiotensina; BRA: bloqueador do receptor 1 da angiotensina II. Valores apresentados em média \pm desvio padrão 
agentes e doses elevadas de diuréticos. Observa-se baixa capacidade funcional, avaliada pela pequena distância percorrida em 6 minutos, e a qualidade de vida se encontrava gravemente comprometida, evidenciada pelo elevado escore no questionário de Minnesota. A função ventricular se encontrava gravemente deprimida, com fração de ejeção muito baixa e elevado diâmetro diastólico do ventrículo esquerdo demonstrados pelo exame ecocardiográfico. A presença de marcante hiponatremia e disfunção renal caracteriza a gravidade dessa população.

Não houve nenhuma complicação relacionada diretamente ao procedimento de coleta ou injeção das células. Os testes de viabilidade indicaram que $96 \pm 6,5$ $\%$ das células eram viáveis. Os marcadores de necrose miocárdica não se alteraram significativamente em 24h, assim como não ocorreram alterações eletrocardiográficas que sugerissem isquemia ou infarto.
Para testar se o implante miocárdico de célulastronco estaria associado à indução de arritmias, o perfil arritmogênico foi avaliado pelo total de extrassístoles ventriculares em 24h, bem como do seu padrão de agrupamento e recorrência. Não foi observada mudança significativa no perfil arritmogênico, embora houvesse tendência não-significativa ao aumento do número de extrassístoles ventriculares em 24h (figura 1), sem mudança no número de episódios de taquicardia ventricular (figura 2).

Ocorreram três óbitos no seguimento de 2 meses de acompanhamento, todos durante o segundo mês (paciente \#04, masculino, 37 anos, hemorragia pulmonar e insuficiência respiratória; paciente \#16, feminino, 34 anos, morte súbita; paciente \#27, 69 anos, masculino, insuficiência cardíaca terminal). Embora esse não seja um estudo de avaliação de eficácia e o parâmetro mortalidade não possa ser avaliado como

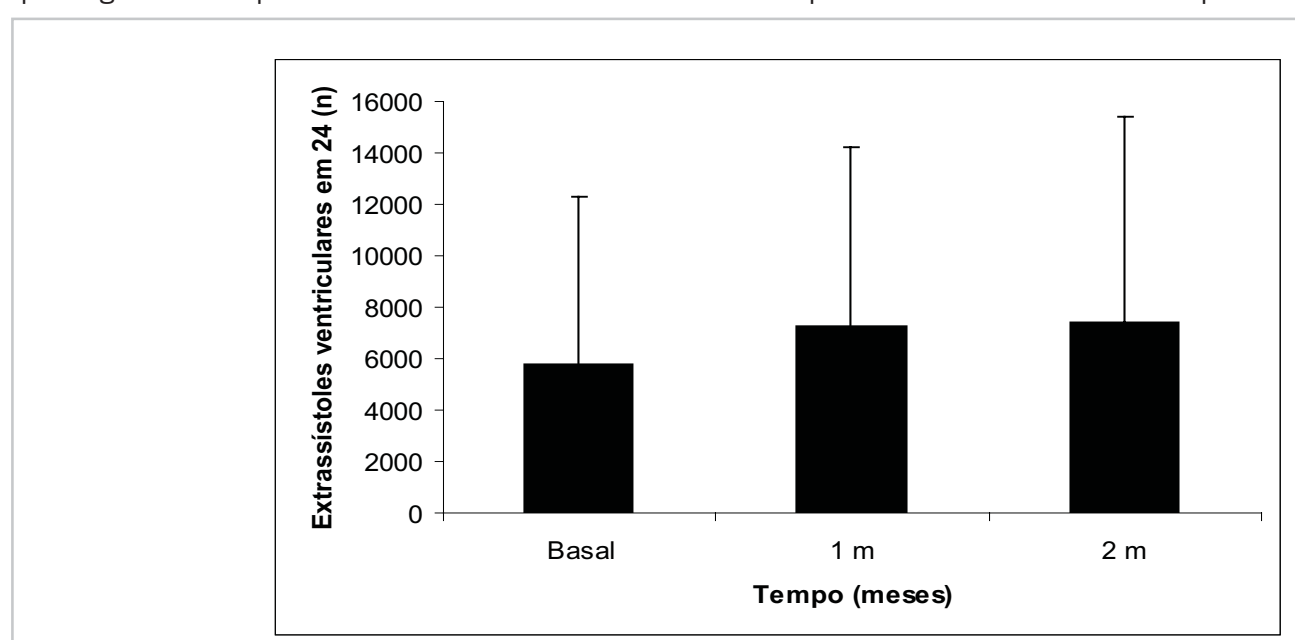

Fig. 1 - Tendência não significativa de elevação do número de extrassístoles ventriculares em $24 h$. EV = extrassístoles ventriculares. $p=0,062$ (Friedman). Barras representam média \pm desvio padrão.

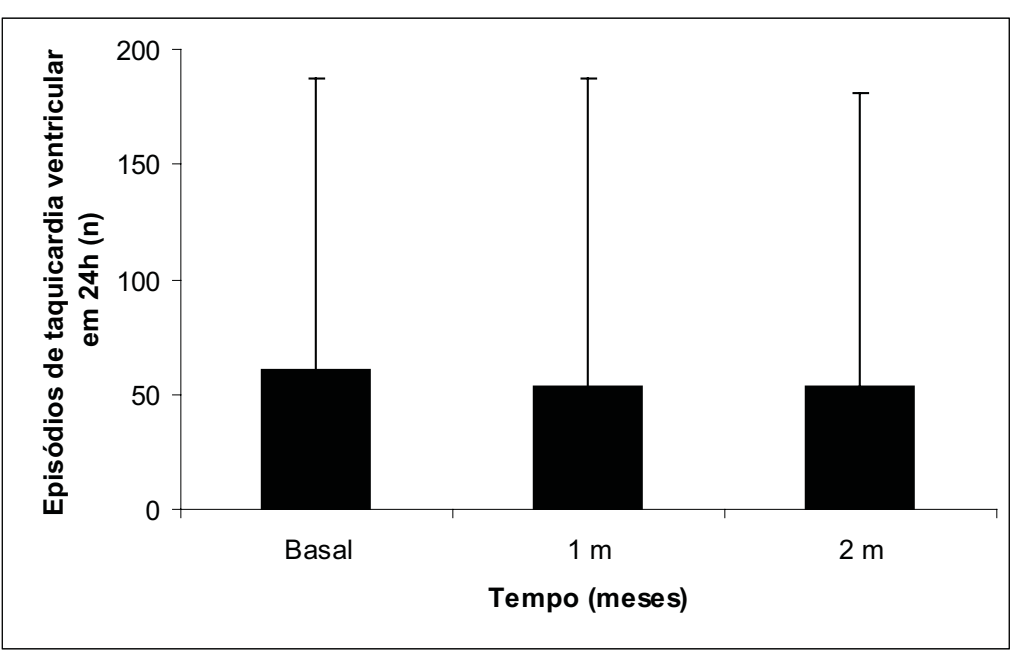

Fig. 2 - Ausência de elevação do número de episódios de taquicardia ventricular em 24h. TV = taquicardia ventricular. $p=N S$ (Friedman). Barras representam média \pm desvio padrão. 
desfecho de segurança, exceto pela associação causal de temporariedade imediata, não identificamos associação causal direta entre o desfecho morte e o procedimento de transplante. Não ocorreram neoplasias, doenças hematológicas, coagulopatias ou qualquer outro tipo de doença que pudesse ser atribuída à injeção das células ou ao seu implante.

A função ventricular apresentou melhora significativa logo após um mês do procedimento, melhora essa que se manteve aos dois meses (figura 3).

A avaliação da qualidade de vida através do questionário de Minnesota revelou melhora significativa do escore global, também com 1 mês, mantida ao longo do período observado (figura 4).

A capacidade funcional avaliada pela distância caminhada no teste de seis minutos em corredor apresentou melhora significativa, mantida por dois meses (figura 5).
Quando analisamos a classe funcional como variável ordinal, observamos redução do valor médio de classe funcional da NYHA, já com 1 mês de acompanhamento, que foi mantida ao longo do período observado (figura 6).

A avaliação bioquímica revelou correção do nível sérico de sódio, entre $72 \mathrm{~h}$ e três semanas do tratamento, correção esta que se manteve durante os dois meses de observação inicial do estudo (figura 7).

\section{Discussão}

Esse é o primeiro estudo a relatar a aplicação de células mononucleares da medula óssea em pacientes com insuficiência cardíaca de etiologia chagásica e o primeiro estudo de terapia celular utilizando modelo não-isquêmico. O nosso modelo envolveu a administração intracoronariana de células, associada ao estímulo medular com filgrastina subcutânea após 30 dias.

A gravidade dos pacientes do presente estudo é maior

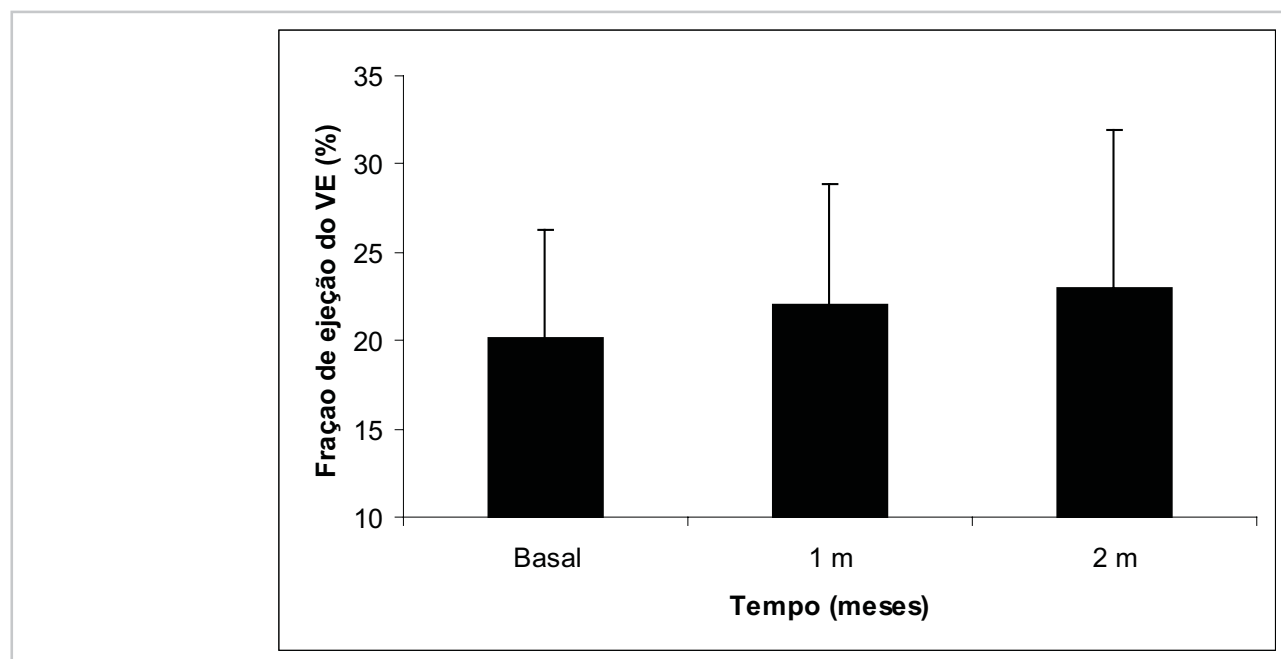

Fig. 3 - Fração de ejeção ventricular esquerda pela ventriculografia radioisotópica. Observa-se elevação após 30 dias, mantida aos 2 meses. $p=0,02$ (Friedman)

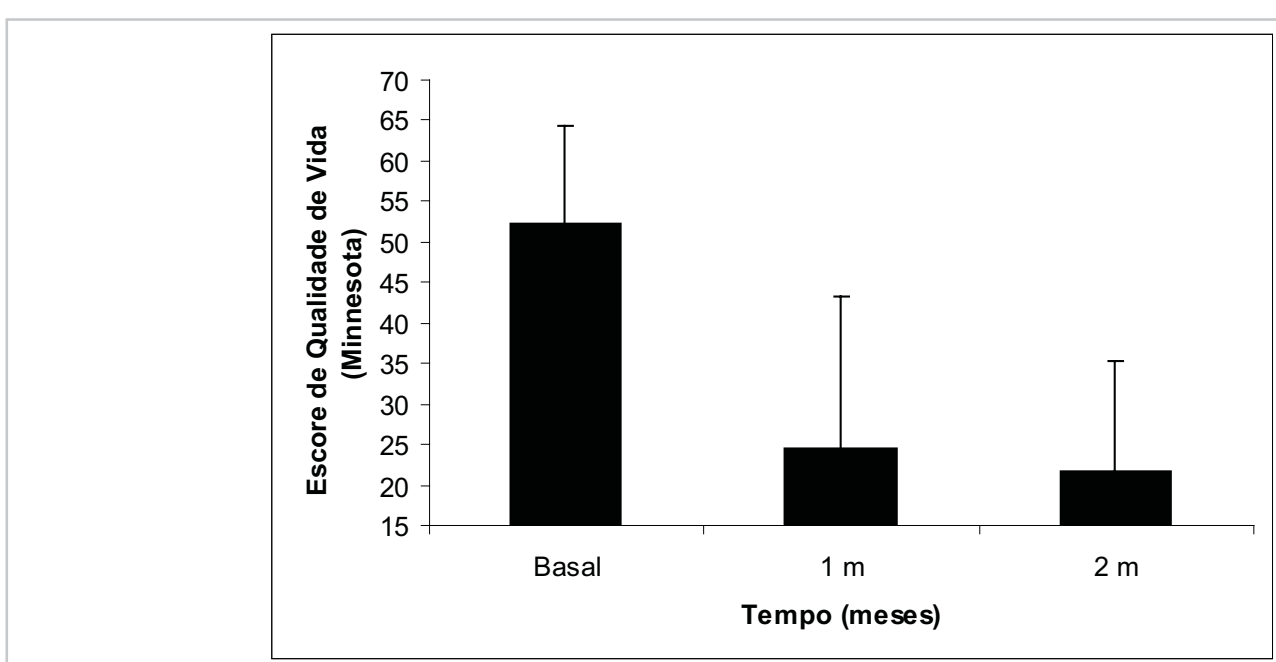

Fig. 4 - Escore de qualidade de vida de Minnesota. Observa-se redução significativa do escore, indicando melhora da qualidade de vida. $p<0,0001$ (Friedman). 


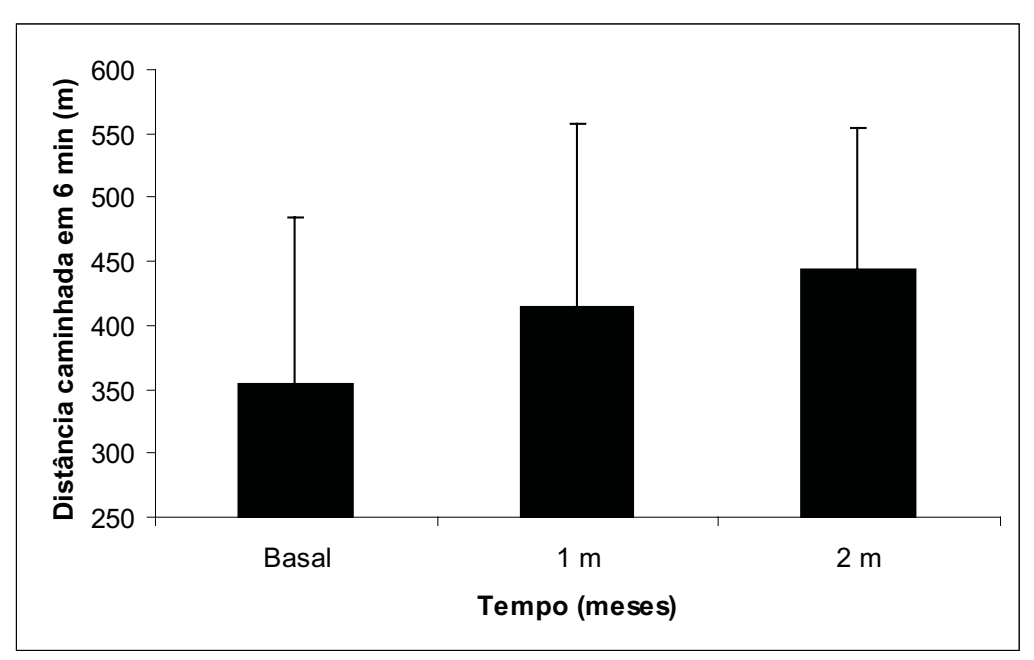

Fig. 5 - Distância caminhada no teste de corredor de 6 minutos. Observa-se significativo aumento após 30 dias, mantido aos 2 meses. $p=0,003$ (Friedman).

que a observada em outros estudos de células-tronco devida a cardiopatia isquêmica, que, via de regra, apresentavam disfunção ventricular, disfunção renal e hiponatremia de menor magnitude. 0 número de células injetadas no presente estudo também foi maior que em outros previamente publicados. Não está claro se há uma relação entre o número de células injetadas e o grau de resposta clínica da terapia celular, mas essa é uma hipótese que precisa ser mais bem explorada.

A observação da não ocorrência de eventos adversos relacionados diretamente ao procedimento indica que o procedimento é exeqüível, desde que seguidos os protocolos implementados no presente estudo, visando a proteção e segurança do paciente.

Um dos aspectos de segurança mais importantes analisados foi a possibilidade de a injeção de células de medula óssea no sistema coronariano causar infarto agudo do miocárdio. Para tanto, foram feitas dosagens de troponina I, CK-MB e análises seriadas de ECG, que não evidenciaram lesão miocárdica, sugerindo que esse procedimento é seguro em relação à indução de isquemia.

Outro importante parâmetro analisado foi o potencial de indução de arritmias. Estudos prévios com o emprego de células-tronco de músculo esquelético (satélites) apresentaram resultados promissores com restauração parcial da função cardíaca, porém tem havido preocupações quanto ao aparecimento de arritmias em pacientes que receberam o tratamento com este tipo celular $^{17,18}$. Em nosso estudo, detectamos aumento nãosignificativo do número de extrassístoles ventriculares isoladas, sem incremento do número de episódios de taquicardia ventricular sustentada ou não.

Em relação aos parâmetros de eficácia, a magnitude dos incrementos na fração de ejeção que observamos foi maior que os descritos previamente em outros estudos. No estudo BOOST ${ }^{19}$, a FEVE média era $52 \%$ e os autores detectaram um aumento médio de $5 \%$, que corresponde a cerca de $10 \%$ de aumento relativo. No presente estudo, nós detectamos um aumento médio semelhante, que corresponde no entanto, a aumento relativo de aproximadamente $20 \%$, já que a FEVE dos nossos pacientes era significativamente menor.

Um achado que chama a atenção é a melhora de qualidade de vida e capacidade funcional. Os pacientes desse estudo estavam em tratamento otimizado, em uso de múltiplos fármacos, em doses otimizadas e persistiam com severa limitação de capacidade funcional e de qualidade de vida. De forma consistente, os pacientes apresentaram melhora da qualidade de vida avaliada pelo questionário de Minnesota, que reflete não apenas parâmetros de dispnéia, mas também aspectos emocionais, psicológicos, econômicos e profissionais. Observação semelhante foi evidenciada em relação a variáveis mais objetivas, como a distância caminhada em 6 min, que é uma medida de exercício em níveis submáximos. Consistente com as variações acima, verificou-se melhora significativa na capacidade funcional avaliada pela classificação da NYHA. Embora aspectos motivacionais possam estar relacionados com essas variáveis subjetivas, a consistência na modificação sugere que é provável haver, realmente, um efeito clínico subjacente. Todos esses achados ocorreram com apenas um mês do tratamento, o que seria precoce demais para considerar devido aos efeitos de transdiferenciação ou fusão celular. Nesse sentido, evidências recentes indicam que o mecanismo de ação que ocorre com o implante de células-tronco envolveria três fenômenos distintos: transdiferenciação, fusão celular e efeitos parácrinos. Essa hipótese se baseia na observação de que efeitos mensuráveis podem ser demonstrados tão cedo quanto apenas $72 \mathrm{~h}^{20}$.

Variáveis mais objetivas, independentes da influência 
de motivação ou sugestão do paciente, bem como de interferência do pesquisador, nos indicam que a terapia empregada exerceu efeitos biológicos positivos. Hiponatremia, por exemplo, é um dos mais importantes marcadores prognósticos na ICC avançada, e o seu mecanismo fisiopatológico está relacionado à ativação neuro-humoral da síndrome ${ }^{21}$. A identificação da correção da hiponatremia em duas semanas, no presente estudo, revela um achado difícil de ser observado na prática clínica, onde mesmo após intervenções terapêuticas otimizadas, dificilmente se observa correção de hiponatremia em pacientes graves.

Os resultados descritos acima, de um modo geral, abrem novas perspectivas para o tratamento de doenças cardíacas através da utilização do potencial regenerador das células-tronco. Nossos dados sugerem que 0 transplante de células-tronco de medula óssea para o miocárdio de pacientes com insuficiência cardíaca de etiologia chagásica é exeqüível, potencialmente seguro e eficaz, trazendo alívio sintomático e melhora de qualidade de vida a uma significativa parcela da população brasileira afetada pelo Mal de Chagas. No entanto, é bastante clara a necessidade de se desenvolver novos estudos no sentido de se esclarecer os mecanismos que levam à melhora pós-terapia, assim como estabelecer protocolos mais eficazes e determinar possíveis riscos e limitações das metodologias empregadas. Embora a identificação precisa das subpopulações envolvidas no processo de reparo seja uma questão importante a ser investigada, deve-se avaliar cautelosamente se processos de purificação destas populações, certamente mais onerosos do que a simples purificação da fração mononuclear que já vem sendo empregada em estudos clínicos, trará maior benefício para os pacientes.

A confirmação desses nossos achados em seguimento mais duradouro, assim como em estudos randomizados e controlados, poderá criar uma nova linha terapêutica que será disponível universalmente, a baixíssimo custo, sem

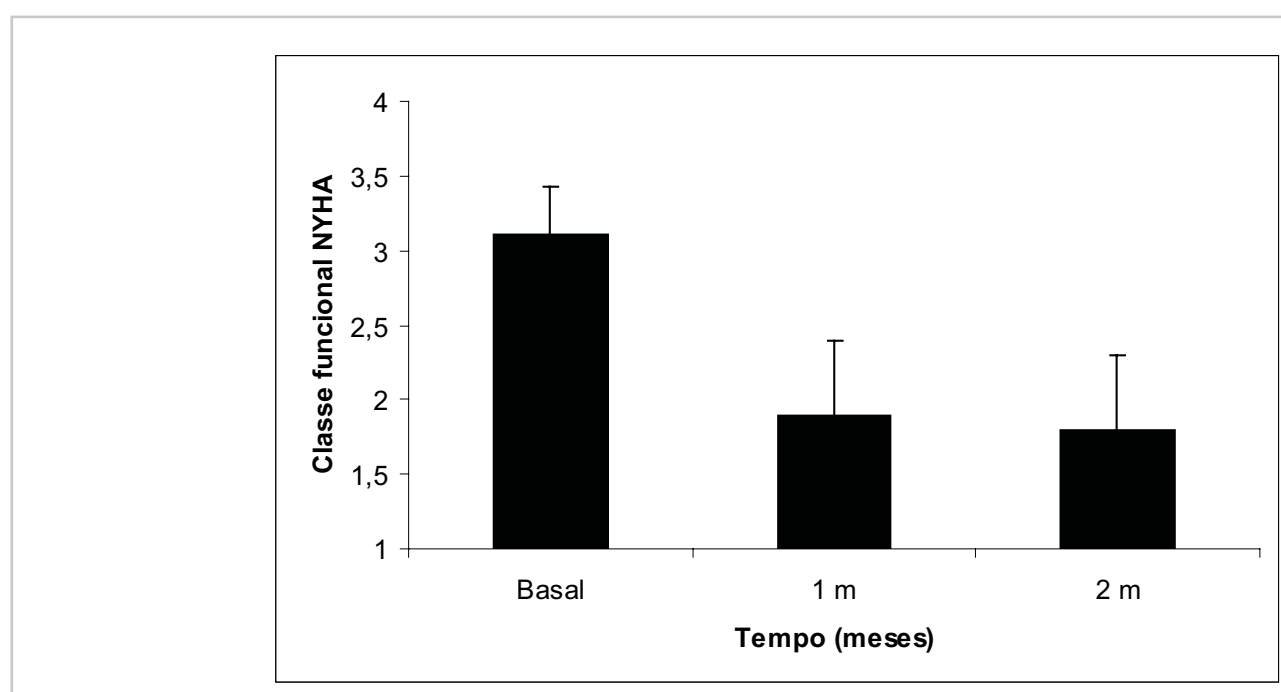

Fig. 6 - Classe funcional média (NYHA) antes e após o tratamento. $p<0,0001$ (Friedman).

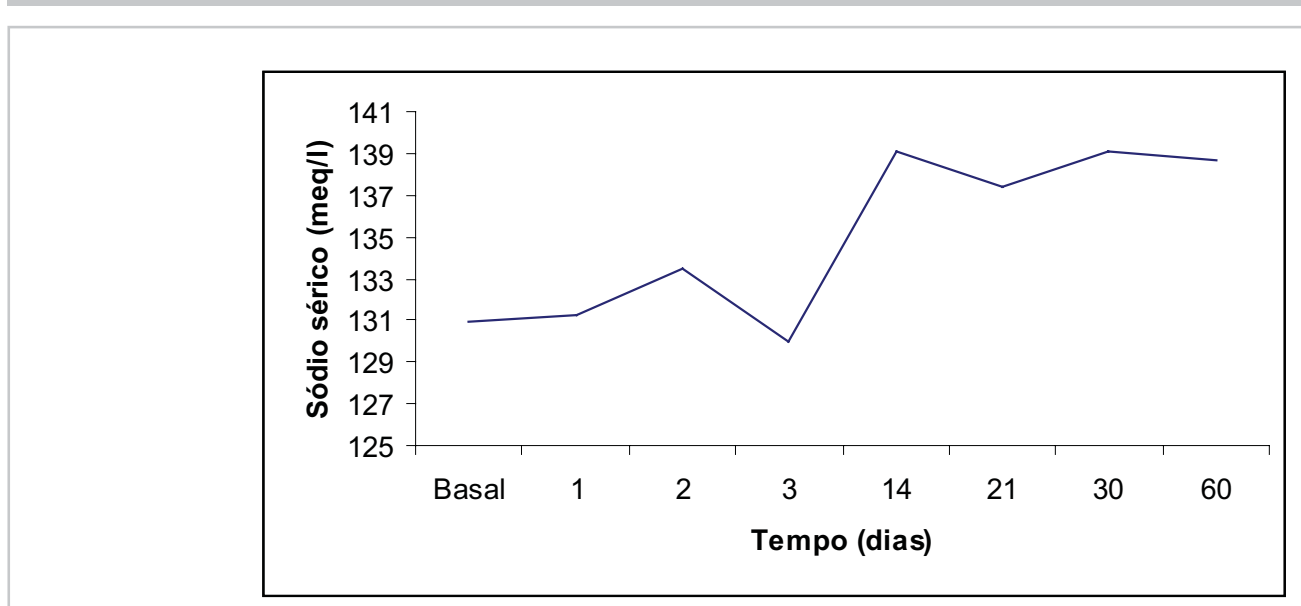

Fig. 7 - Concentração de sódio sérico antes e após o tratamento. Observa-se entre $72 h$ e 2 semanas, correção das concentrações de sódio, que se mantêm normais até o final do estudo (Friedman, $p<0,0001$ ). 
rejeição, sem medicação especifica, mais fisiológica, menos agressiva e com possibilidades múltiplas de repetição.

\section{Agradecimentos}

Os autores desejam expressar seus agradecimentos às enfermeiras Cristiane Carvalho e Aline Bernardes, do Núcleo de Pesquisas em Cardiologia do Hospital Santa
Izabel, pela assistência aos pacientes durante todo o estudo. A contribuição de Daniele Brustolim, do Centro de Pesquisas Gonçalo Moniz - Fundação Oswaldo Cruz - Bahia nos procedimentos de separação celular é reconhecido com destaque.

\section{Potencial Conflito de Interesses}

Declaro não haver conflitos de interesses pertinentes.

\section{REFERÊNCIAS}

1. Orlic D. Stem cell repair in ischemic heart disease: An experimental model. Intern J Hematol. 2002; 76 (Suppl. 1): 144-5.

2. Orlic D, Kajstura J, Chimenti S, Jakoniuk I, Anderson SM, Li B, et al. Bone marrow cells regenerate infarcted myocardium. Nature. 2001; 410: 701-15.

3. Orlic D, Kajstura J, Chimenti S, Bodine DM, Leri A, Anversa P. Transplanted adult bone marrow cells repair myocardial infarcts in mice. Ann NY Academy Sci. 2001; 938: 221-9.

4. Assmus B, Schachinger V, Teupe C, Britten M, Lehmann R, Dobert N, et al. Transplantation of progenitor cells and regeneration enhancement in acute myocardial infarction (TOPCARE-AMI). Circulation. 2002; 106: 3009-17.

5. Perin EC, Dohmann HF, Borojevic R, Silva SA, Sousa AL, Mesquita CT. Transendocardial, autologous bone marrow cell transplantation for severe, chronic ischemic heart failure. Circulation. 2003; 107: 2294-302

6. Stamm C, Westphal B, Kleine HD, Petzsch M, Kittner C, Klinge H, et al. Autologous bone-marrow stem-cell transplantation for myocardial regeneration. Lancet 2003; 361: 45-6.

7. Dias JCP, Silveira AC, Schofield CJ. The impact of Chagas disease control in Latin America: a review. Mem. Inst. Oswaldo Cruz. 2002; 97(5): 603-12

8. Soares MBP, Pontes-de-Carvalho L, Ribeiro-dos-Santos R. The pathogenesis of Chagas' disease: when autoimmune and parasitespecific immune responses meet. Ann Acad Bras Cienc. 2001; 73: 547-59.

9. Vilas-Boas F, Ribeiro-dos-Santos R, Soares MBP, et al. Identification of regional differences in proinflammatory cytokine concentrations in chronic heart failure due to Chagas' cardiomyopathy: a key element in the comprehension of the disease. J Am Coll Cardiol. 2003; 41: 155A

10. Soares MBP, Lima RS, Rocha LL, et al. Transplanted bone marrow cells repair heart tissue and reduce myocarditis in chronic chagasic mice. Am J Pathology. 2004 Feb; 164(2): 441-7.

11. Vilas-Boas F, Feitosa GS, Soares MBP, Pinho-Filho JA, Mota A, Almeida AJG. Bone Marrow Cell Transplantation to the Myocardium of a Patient with Heart Failure Due to Chagas' Disease. Arq Bras Cardiol. 2004;
82: 185-7.

12. Bittner V, Weiner DH, Yusuf S, et al. Prediction of mortality and morbidity with a 6-minute walk test in patients with left ventricular dysfunction. JAMA. 1993; 270: 1702-7.

13. Rector TS, Kubo SH, Cohn JN. Patients self-assessment of their congestive heart failure: content, reliability and validity of a new measure, the Minnesota Living with Heart Failure questionnaire. Heart Failure. 1987; 3: 198-209.

14. Carrara D. Avaliação prospectiva da qualidade de vida em pacientes com miocardiopatia dilatada submetidos a ventriculectomia parcial esquerda. Dissertação de Mestrado apresentada à Faculdade de Medicina da Universidade de São Paulo, 2001; p.18-21.

15. Schiller NB, Shah PM, Crawford M, et al. Recommendations for quantitation of the left ventricle by two-dimensional echocardiography: American Society of Echocardiography Committee on Standards. Subcommittee on Quantitation of Two-Dimensional Echocardiograms. J Am Soc Echocardiogr. 1989; 2: 385-97.

16. Stewart WJ, Rodkey SM, Gunawardena S, et al. Left ventricular volume calculation with integrated backscatter from echocardiography. J Am Soc Echocardiogr. 1993; 6(6): 553-63.

17. Murry CE, Wiseman RW, Schwartz SM, Hauschka SD. Skeletal myoblast transplantation for repair of myocardial necrosis. J Clin Investigation. 1996; 98, 2512-2523.

18. Menasche P, Hagege AA, Vilquin JT, Desnos M, Abergel E, Pouzet $B$, et al. Autologous skeletal myoblast transplantation for severe postinfarction left ventricular dysfunction. J Am Coll Cardiol. 2003 Apr 2; 41(7):1078-83.

19. Wollert KC, Meyer GP, Lotz J. Intracoronary autologous bone-marrow cell transfer after myocardial infarction. BOOST trial. Lancet. 2004;364:141-48

20. GnecchiM, He H, Liang OD, Melo LG, Morello F, Mu H, et al. Paracrine action accounts for marked protection of ischemic heart by Akt-modified mesenchymal stem cells. Nature Medicine. 2005;11:367-68.

21. Packer M, Lee WH, Kessler PD, et al. Role of neurohormonal mechanisms in determining survival in patients with severe chronic heart failure. Circulation. 1987;75 (Suppl 4):80. 